\title{
Review on Modification of Sulfonated Poly (-ether-ether-ketone) Membranes Used as Proton Exchange Membranes
}

\author{
Xiaomin GAO $^{1 *}$, Yonghua LIU ${ }^{1}$, Jinlong LI ${ }^{2}$ \\ ${ }^{1}$ Institute of Chemical Materials, CAEP. Mianyang, Sichuan, China, 621900 \\ ${ }^{2}$ Chongqing BOE Optoelectronics Technology Co., Ltd., Chongqing, 400700 \\ cross $^{\text {ref }}$ http://dx.doi.org/10.5755/j01.ms.21.4.9712
}

\section{Received 28 January 2015; accepted 03 October 2015}

\begin{abstract}
The proton exchange membrane fuel cell (PEMFC) is a type of modern power, but the traditional proton exchange membranes (PEM) of PEMFC are limited by high methanol permeability and water uptake. Poly-ether-ether-ketone (PEEK) is a widely used thermoplastic with good cost-effective property. Sulfonated poly (-ether-ether-ketone) (SPEEK) has high electric conductivity and low methanol permeability, as well as comprehensive property, which is expected to be used as PEMs. However, the proton exchange ability, methanol resistance, mechanical property and thermal stability of SPEEK are closely related to the degree of sulfonation (DS) of SPEEK membranes. Additionally, the proton conductivity, methanol permeability, and stability of SPEEK membranes applied in various conditions need to be further improved. In this paper, the research into modification of SPEEK membranes made by SPEEK and other polymers, inorganic materials are introduced. The properties and modification situation of the SPEEK and the composite membranes, as well as the advantages and disadvantages of membranes prepared by different materials are summarized. From the results we know that, the methanol permeability of SPEEK/PES-C membranes is within the order of magnitude, $10^{-7} \mathrm{~cm}^{2} / \mathrm{s}$. The proton conductivity of the SPPESK/SPEEK blend membrane reaches $0.212 \mathrm{~S} \mathrm{~cm}^{-1}$ at $80{ }^{\circ} \mathrm{C}$. The cross-linked SPEEK membranes have raised thermal and dimensional stability. The non-solvent caused aggregation of the SPEEK ionomers. The proton conductivity of SPEEK/50\%BMIMPF 6 /4.6PA membrane maintains stable as $2.0 \times 10^{-2} \mathrm{~S} \mathrm{~cm}^{-1}$ after $600 \mathrm{~h}$ at $160{ }^{\circ} \mathrm{C}$. Incorporation of aligned CNT into SPEEK increases the proton conductivity and reduces the methanol permeability of the composite membranes. The PANI improves the hydrothermal stability. More proton transfer sites lead to a more compact structure in the composite membranes. According to the results, the proton exchange capacity, water uptake, and conductivity of the SPEEK membranes are closely related to the structure, stability, mechanical and electrochemical property and methanol permeation of the PEMFC. The modification of SPEEK membranes will improve their applications in aviation, military and other industries. Some proposals for further research are put forward.

Keywords: sulfonated poly (-ether-ether-ketone), proton exchange membrane, modification.
\end{abstract}

\section{INTRODUCTION}

The renewable and clean energy is one of the pressing international demands in the world [1].

As a kind of modern power of dynamo-electric vehicle, proton exchange membrane fuel cell (PEMFC) has high efficiency and energy density, it is harmless to environment [2-3]. As a barrier to the fuel gas between the electrodes, proton exchange membrane (PEM) plays key role in transferring protons from the anode to cathode of the PEMFC. The membranes traditionally used in PEMFC are perfluorosulfonic polymers such as Dupont Nafion, which have high proton exchange ability and good chemical stability. However, some disadvantages limited their further application, their water uptake, methanol permeability and cost are quite high at certain conditions [4]. So many research works have been focused on developing the PEM with more comprehensive performance. Poly-ether-ether-ketone (PEEK) is a kind of thermoplastic with good cost-effective property [5-7]. It is widely used in space-flight, petroleum, chemical and medical industrial fields because of its heat and corrosion resistant, outstanding toughness and machining property [8-11]. SPEEK has high electric conductivity and low

\footnotetext{
* Corresponding author. Tel.: +86-0816-2485376; fax: +86-08162495856. E-mail address: info_icm@caep.cn (X.Gao)
}

methanol permeability, as well as high ion exchange capacity (IEC), good mechanical property and stability, which is expected to be used as PEM to replace the Nafion materials [12-15]. But the main properties of the SPEEK depend on the DS, preparation process of SPEEK membranes. Besides, demands from various areas need higher quality SPEEK membranes. This paper introduces the modification of SPEEK membranes.

\section{MODIFICATION OF SPEEK MEMBRANES}

The proton exchange ability, methanol resistance, mechanical property and thermal stability of SPEEK are closely related to the DS [13, 16-22]. The membranes with low DS are methanol and swelling resistant but have poor proton exchange abilities [15]. The membranes, with high DS, have high proton exchange and water uptake ability, but the methanol and swelling resistance decrease [14]. Moreover, The SPEEK membranes used in different environment, such as various temperature and humid conditions, should possess improved comprehensive properties. So the SPEEK membranes need to be modified to enhance the proton conductivity, methanol resistance, thermal, dimensional and mechanical stability. Composite membranes of SPEEK modified with polymers are common technology for improving the mechanical property, water uptake, and the stability and selectivity of 
the membranes in high temperature environment. Additionally, in order to achieve acceptable proton conductivity, high degree of functionalization is required, but the excessive water swelling of SPEEK would weaken the methanol barrier ability and mechanical property [23]. Developing organic-inorganic composite membranes is a feasible and effective way to solve the above problems. The SPEEK membranes can be modified by polymers and inorganic fillers to achieve composite membranes with improved properties.

\section{MODIFICATION OF SPEEK MEMBRANES WITH POLYMERS}

A variety of modification approaches such as crosslinking and blending have been explored to prepare efficient membranes based on SPEEK [24].

\subsection{The blend membranes of SPEEK with polymers}

The blend membranes of SPEEK with polymers will further improve swelling, methanol permeability, and enhance the proton conductivity of SPEEK membranes, and meet the demands of service life and stability for the membranes in various temperature and humid conditions [25].

The high proton conductivity of the membranes need high DS and service ability at elevated temperature, but the SPEEK membrane with fairly high DS can swell excessively and even dissolve at high temperature. For this reason, phenolphthalein poly (-ether sulfone)(PES-C) and sulfonated phenolphthalein poly (-ether sulfone)(SPES-C, $\mathrm{DS}=53.7 \%$ ) were blended into SPEEK polymer to prepare SPEEK/PES-C and SPEEK/SPES-C composite membranes by GAO Qijun et al. [26]. The results revealed that the two blended polymers show good miscibility. Both PES-C and SPES-C could decrease the swelling degree and methanol permeability effectively. Pure SPEEK membrane dissolved completely at $75^{\circ} \mathrm{C}$, the swelling degree of SPEEK/PES-C (30\%) and SPEEK/SPES-C (30\%) were $22.5 \%$ and $26.32 \%$ at $80{ }^{\circ} \mathrm{C}$, respectively. From room temperature to $80{ }^{\circ} \mathrm{C}$, the methanol permeability of blend membranes were within the order of magnitude, $10^{-7} \mathrm{~cm}^{2} / \mathrm{s}$, which was about one order of magnitude lower than that of Nafion $® 115$. Under $100 \%$ $\mathrm{RH}$, the proton conductivity of blend membranes with 20 wt.\% PES-C exceeded that of Nafion $® 115$ at above $90{ }^{\circ} \mathrm{C}$, the proton conductivity of blend membranes with 30 wt. $\%$ SPES-C reached $0.11 \mathrm{~S} \mathrm{~cm}^{-1}$, comparable to Nafion®1 15 at $110^{\circ} \mathrm{C}$.

The sulfonated poly (phthalazinone ether sulfone ketone) (SPPESK) with low swelling rate and the SPEEK with good water uptake were used to prepare SPPESK/SPEEK blend proton exchange membrane by Du Liguang et al. [27]. The results showed that the water uptake and swelling rate of the SPPESK/SPEEK blend membrane were $101 \%$ and $34 \%$ at $80{ }^{\circ} \mathrm{C}$, respectively. The methanol swelling rate and the proton conductivity of the blend membrane was $20 \%$ and $0.212 \mathrm{~S} \mathrm{~cm}^{-1}$ at $80{ }^{\circ} \mathrm{C}$. The flexibility of the blend membrane was better than that of SPPESK. The SPEEK improved the increase of tensile strain, from $16.48 \%$ to $30.43 \%$.
SPEEK and fluorinated polymer based blends for low temperature $\left(<80^{\circ} \mathrm{C}\right)$ fuel cell applications were prepared by Inan Tülay Y. et al. [28]. The results showed that the water uptake and proton conductivity values decreased with the addition of fluorinated polymers (PVDF, PVDFHFP) as expected, but proton conductivity values were still comparable to that of Nafion 117 membrane. The fluorinated polymers improved the chemical degradation of the blend membranes, yet addition of the PVDF-HFP to the SPEEK70 caused phase separations. The methanol permeability of SPEEK70/PVDF blend membrane $\left(3.13 \times 10^{-7} \mathrm{~cm}^{2} / \mathrm{s}\right)$ was much lower than Nafion 117 $\left(1.21 \times 10^{-6} \mathrm{~cm}^{2} / \mathrm{s}\right)$. Hydrogen and oxygen permeability values were $1 / 10$ and $1 / 5$ of the Nafion, respectively.

The results of preparation of blend membranes of SPEEK show that the PES-C and SPES-C appear good miscibility with SPEEK. The swelling and methanol permeability are reduced effectively by adding the PES-C and SPES-C into SPEEK. The blended membranes of SPPESK and SPEEK can bear methanol with higher concentration, which has better proton conductivity. The compatibility between PVDF-HFP and SPEEK is quite good. The chemical degradation and methanol permeability of the blended membranes are promoted by the PVDF and PVDF-HFP.

\subsection{The cross-linked membranes by EB irradiation of SPEEK with polymers}

Presently, the radiation-induced cross-linking method utilizing electron beam (EB) has been widely used for polymeric material processing due to their inherent advantages over UV and thermal curing methods. The radiation cross-linking strategy using a cross-linker into SPEEK based membranes is a simple and efficient way, to increase thermal and dimensional stability, mechanical properties of the membranes, and simultaneously, to reduce the methanol permeability and maintain proton conductivity [29]. Song Ju-Myung et al. prepared crosslinked SPEEK membranes by the radiation cross-linking of SPEEK with various cross-linkers, such as polyester acrylate, trimethyol propane triacrylate (TMPTA), 1,6hexandial diacrylate (HDDA), and 2-(2-ethoxyethoxy)ethyl acrylate (EOEOA). They found that the crosslinked membranes have higher cluster $T g$ than Nafion 117 membrane, which indicated that the cross-linked membranes could be more useful than Nafion 117 membrane in high temperature fuel cell. The SAXS data showed that the used cross-linker did not affect the ionic domain morphology in the membranes. The proton conductivity of all the membranes exceeded $10^{-2} \mathrm{~S} \mathrm{~cm}^{-1}$. The cross-linked SPEEK membranes, with better thermal and dimensional stability, would possibly improve the performance of PEMFC, especially, at high temperature $\left(90{ }^{\circ} \mathrm{C}\right)$.

In order to mitigate problems associated with dimensional stability, mechanical strength, and methanol crossover, the 1,6-bis (4- vinylphenyl) hexane (BVPH), an unhydrolyzable cross-linker, was prepared and used to cross-link SPEEK membranes by EB irradiation by Han Sanghee et al. at room temperature [30]. Compared to the pristine SPEEK membrane, the cross-linked membranes 
exhibited significantly improved dimensional and chemical stability, and mechanical strength. The cross-linking of SPEEK with BVPH slightly reduced the proton conductivity of the membranes, but significantly reduced the methanol permeability

Cross-linked SPEEK membranes were prepared using an EB-irradiation cross-linking method with various contents of cross-linker mixture (1,4-butanediol divinyl ether (BDVE)/triallyl isocyanurate (TAIC), 9/1 wt. ratio) and applied as PEM for fuel cell application by Song JuMyung et al. [31]. They found that the degree of crosslinking and the chemical stability of the EB-cross-linked SPEEK membranes were enhanced by the increase of the BDVE/TAIC cross-linker content from gel fraction results. Nevertheless the water uptake, IEC, and proton conductivity of the cross-linked membranes decreased with the content increase of the cross-linker mixture. The DMA and SAXS data indicated that the EB-cross-linked SPEEK membrane have well-developed ionic aggregation in the cluster regions. In addition, the current density of the cross-linked membranes was higher than $1198 \mathrm{~mA} / \mathrm{cm}^{2}$ at a 0.4 voltage (V) under fully hydrated condition at $80^{\circ} \mathrm{C}$ with a 1.5 bar backpressure from a MEA cell performance test. Compared to the pristine SPEEK membrane, the cross-linked membranes achieved by EB irradiation, exhibit significantly improved dimensional, thermal and chemical stability, and mechanical strength. The crosslinking process slightly decreases the proton conductivity but significantly reduce the methanol permeability of the SPEEK membranes. So, it can be seen that the crosslinking process is very effective way for improving the properties of the SPEEK membranes, and the membranes could be more useful than Nafion 117 in high temperature fuel cell.

\subsection{The modification of SPEEK membranes with other polymers}

A series of semi-interpenetrated polymer network (semi-IPN) combining fluorinated hexane network and linear SPEEK (L-SPEEK) were obtained by varying the SPEEK content from 50 to $80 \mathrm{wt} \%$ by Linda Chikha et al. [32]. These semi-IPNs displayed good thermal stability and moderated water uptake swelling. Their chemical stabilities in the Fenton reagent were estimated to be 10 times higher than that of the L-SPEEK.

PTFE has good compatibility with Nafion resin because of their similar chain structures. A composite membrane based on SPEEK and porous PTFE was prepared by Bi Cheng et al. [33]. The PTFE substrate was hydrophilically pretreated by naphthalene sodium solution. The results indicated that the SPEEK can impregnate into treated PTFE substrate (trPTFE) easily. The mechanical property of SPEEK/trPTFE membrane has advantages over pristine SPEEK membrane. Thinner composite membrane would be applied in single cell due to the reinforced effect of trPTFE on substrate.

Liu D. et al. prepared long cross-linked composite membranes, in which, the SPEEK particles were dispersed in a non-proton conductive polymeric matrix, a crosslinked poly(dimethyl siloxane) (PDMS) [34]. Experimental results indicated that the long SPEEK chains improved the conductivity of the membrane, water uptake, and dimensional stability, and the chains also caused the increase of the methanol permeation. The membranes displayed anisotropic swelling behavior in water which then promotes the enhancing of the mechanical stability in humidity cycling.

PEEK and SPEEK were synthesized via nucleophilic aromatic substitution reaction, then the bromomethylated poly(ether ether ketone) (PEEK-Br) was prepared and reacted with 2-benzimidazolethiol to obtain the benzimidazole grafted poly(ether ether ketone) (PEEK-BI) by Li Hongtao et al. [35]. The results showed that the composite membranes exhibit better mechanical properties as well as reduced water uptake and methanol permeability than the pristine SPEEK membrane. The increased oxidative stability and selectivity indicated that the composite membranes are promising to be used as PEM.

Polymer electrolyte membranes (PEMs) were developed for DMFC applications, based on SPEEK and polyvinylidene fluoride-co-hexafluoropropylene (PVDFHFP) filled with Cloisite 30B (C 30B) as a solid hydrophilic proton conductor [36]. PEMs were characterized using liquid uptake, oxidative stability, TGA, XRD, SEM, AFM and impedance analysis. The single cell DMFC performance revealed that the optimized PEM showed an open circuit voltage (OCV) of $0.79 \mathrm{~V}$ and a maximum power density value of $55 \mathrm{~mW} \mathrm{~cm}^{-2}$ with a proton conductivity value in the range of $10^{-2} \mathrm{~S} \mathrm{~cm}^{-1}$. The methanol permeability and selectivity ratio of the optimized membrane were $1.35 \times 10^{-7} \mathrm{~cm}^{2} \mathrm{~s}^{-1}$ and $9.63 \times 10^{4} \mathrm{~S} \mathrm{~s} \mathrm{~cm}^{-3}$, respectively. As a result fabricated membranes could be seen as promising PEMs for DMFC applications.

Membrane casting solution of SPEEK dispersed in the mixture of solvent dimethyl formamide (DMF) and nonsolvent (tetrachloroethylene or paraxylene) was used to prepare SPEEK electrolyte membranes by ZHANG LiJuan et al. [37]. The proton conductivity and water permeability were increased by around $50 \%-60 \%$ and $30 \%$ respectively, compared to the membrane casting from SPEEK/DMF solution. The non-solvent caused aggregation of the SPEEK ionomers, which then affected the structure and performance of the resultant membranes.

Reviewing the properties of composite membranes of SPEEK, we can find that the semi-IPNs composed of fluorinated hexane network and L-SPEEK display good thermal stability and moderated water uptake and swelling. The membranes made of trPTFE and PEEK show excellent mechanical properties. The long cross-linked chains formed by suspension SPEEK particles improve the proton conductivity, water uptake and dimensional stability of the membranes. The composite membranes of PEEK-Br and PEEK-BI exhibit greatly improved mechanical properties, water uptake and methanol permeability, the oxidative stability and selectivity increased as well. The introduction of PVDF-HFP/C 30B improves the dimensional, thermal and oxidative stabilities of PEMs. The obtained methanol permeabilities of the membranes are lower than that of Nafion ${ }^{\circledR}$ 117. Compared to the SPEEK/DMF membranes, the non-solvent used in the SPEEK membranes increased the proton conductivity and water permeability by around 
$50 \%-60 \%$ and $30 \%$ respectively, but the non-solvent caused aggregation of the SPEEK ionomers.

\section{MODIFICATION OF SPEEK MEMBRANES WITH INORGANIC MATERIALS}

For practical use, PEM must possess excellent mechanical properties and high proton conductivity simultaneously [38]. The organic-inorganic composite membranes would combine the remarkable mechanical property of the polymer matrix with the high intrinsic conductivities of the inorganic additives. At the same time, the inorganic components can suppress excessive water swelling and methanol crossover, while improving mechanical and thermal stabilities of the composites [39].

\subsection{Modification of SPEEK membranes with $\mathrm{SiO}_{2}$ materials}

Silicon dioxide $\left(\mathrm{SiO}_{2}\right)$ is widely used for composite membranes due to its good mechanical properties and water retention [23]. A series of organic/inorganic hybrid materials based on $\mathrm{SPEEK} / \mathrm{SiO}_{2}$ were used to produce electrolytic membranes for DMFC.

$\mathrm{XU}$ Dan et al. prepared $\mathrm{SPEEK} / \mathrm{SiO}_{2}$ composite membranes based on sulfonated silica/ SPEEK by means of sol-gel method so as to gain high conductivity and reasonable methanol permeability [40]. The sulfonated silica was generated in situ via the hydrolysis of sulfonated 3-anminopropyl triethoxysilane(KH550). The membrane with silica mass fraction of $5 \%$ exhibited conductivity of $0.187 \mathrm{~S} \mathrm{~cm}^{-1}$ and methanol coefficient of $9.72 \times 10^{-7} \mathrm{~cm}^{2} / \mathrm{s}$ at $80{ }^{\circ} \mathrm{C}$. The composite membranes showed better conductivity and selectivity which are promising for DMFC application.

Vijay Shankar Rangasamy et al. investigated the effect of the silica functionalisation route on the thermal, mechanical and structural properties of SPEEK-silica composite membranes [41]. They compared two different methods - direct sulfonation and co-condensation (sol-gel) to add sulfonic acid groups to silica nanoparticles, which were used as fillers in SPEEK membranes. The DS of the cast membranes determined by ${ }^{1} \mathrm{H}$ NMR ranged from $40 \%$ to $86 \%$. TGA-DSC measurement showed higher desulfonation temperatures for the composite membranes, indicating better thermal stability compared to pure SPEEK membranes. DMA results showed that the sol-gel membranes were mechanically more stable within a wider operational temperature range than the directly sulfonated and pristine SPEEK membranes. Water uptake of the membranes increased with silica content, indicating the formation of additional water-mediated pathways for proton conduction.

Du Lin investigated the sulfonation conditions and the swelling resistance of the SPEEK with various DS, to determine the suitable scope of DS in SPEEK for inorganic modification [39]. The silica sulfuric acid (SSA) and the superacid tin oxide $\left(\mathrm{SSnO}_{2}\right)$ nanoparticles were synthesized, and the SPEEK/SSA and SPEEK/SSnO composite membranes were characterized respectively. The results showed that high-DS SPEEK has poor swelling resistance and the SPEEK with DS within 50\%-60\% has good mechanical stability in water. The SPEEK/SSA composite membrane doped with $5 \mathrm{wt} \%$ SSA nanoparticles showed the best performance at $80{ }^{\circ} \mathrm{C}$, the water uptake of the membrane was $56.4 \%$, conductivity was $0.13 \mathrm{~S} \mathrm{~cm}^{-1}$, which is $18.6 \%$ higher than that of SPEEK membrane. The composite membranes also exhibited higher water uptake and conductivity than the SPEEK membrane. When the relative humidity ( $\mathrm{RH})$ was $40 \%$ and $80 \%$ at $80{ }^{\circ} \mathrm{C}$, the conductivity of SPEEK-5SSA was $166.4 \%$ and $48.5 \%$, higher than the pristine SPEEK membrane, respectively. The conductivity and elastic modulus increased, whereas the swelling ratio decreased with the increase of the $\mathrm{SSnO}_{2}$ content.

Among a variety of fillers, polyhedral oligomeric silsesquioxane (POSS) has drawn a considerable attention in last few years. A typical POSS macromere is a cage-like hybrid molecule of silicon and oxygen, ranging from approximately $1-3 \mathrm{~nm}$ in size [42]. They have chemical composition of $\mathrm{RSiO}_{1.5}$, similar to both silica $\left(\mathrm{SiO}_{2}\right)$ and silicons $\left(\mathrm{R}_{2} \mathrm{SiO}\right)_{\mathrm{n}}$. Conceptually, POSS itself may be thought of as the smallest particle of silica. POSS is rigid and inert like inorganic filler, and can molecularly dissolve in a polymer matrix. Novel hybrid composite membranes were prepared by blending poly (-ethylene glycol) functionalized polyhedral oligomeric silsesquioxane [PPOSS], as nanofiller in varying concentration ranging from 1 to $5 \%$ (w/w), into SPEEK by Deeksha Gupta et al. The effect of incorporation of PPOSS into SPEEK matrix was investigated in terms of thermomechanical and morphological properties, water uptake and proton conductivity of SPEEK. All the composite membranes were thermally and mechanically stable up to $250{ }^{\circ} \mathrm{C}$. Transmission electron microscopy (TEM) revealed the small particle size $(\sim 100 \mathrm{~nm}, 2 \mathrm{wt} . \%)$ of PPOSS dispersed in SPEEK membranes, and agglomeration of PPOSS $(\sim 300 \mathrm{~nm})$ was observed at higher loading. The proton conductivity was found to be dependent on the morphology and was independent of the amount of water present in the membranes. The highest proton conductivity (0.047 $\mathrm{S} \mathrm{cm}^{-1}$ compared $0.034 \mathrm{~S} \mathrm{~cm}^{-1}$ for net SPEEK) gained at $100{ }^{\circ} \mathrm{C}$ and $100 \% \mathrm{RH}$.

Summary of properties of composite membranes of SPEEK containing $\mathrm{SiO}_{2}$ implying that the interaction between the functional groups of silica and the sulfonic groups of polymer can influence the water uptake, swelling and conductivity of the membranes. The IEC, water uptake and swelling measurements highlight that the silica contributes to reduce the swelling through interactions between sulphonic and aminic groups. The composite membranes prepared by reduced SPEEK and isocyanate propyl trioxethyl silane have lower methanol permeability and similar proton conductivity than Nafion membrane, the thermal and dimensional stability increase with the increase of $\mathrm{SiO}_{2}$ in the membranes. The $\mathrm{SiO}_{2}$ is helpful for improving the form of compact structure and then raise the mechanical stability and the swelling resistance. The $\mathrm{SiO}_{2} / \mathrm{SPEEK}$ membranes show improved conductivity and better selectivity. The SPEEK/SSA and SPEEK/SSnO composite membranes, with DS in the range of $50 \%-60 \%$, have good mechanical stability in water. The SPEEK/SSA membranes doped with 5 wt. $\%$ SSA show the best performance. The SPEEK-silica composite membranes show better thermal and mechanical stability 
compared to pure SPEEK membranes within wider operational temperature range. The formation of watermediated pathways for proton conduction improves the water uptake of the membranes. The incorporation of varying amounts of PPOSS into SPEEK matrix results thermally, mechanically and hydrolytically stable composite membranes with increased proton conductivity. The composite membranes showed higher water uptake and proton conductivity as compared to that of neat SPEEK membranes. However, agglomeration occurs after certain concentration of PPOSS.

\subsection{Modification of SPEEK membranes with CNTs materials}

Carbon nanotubes (CNTs) are one of the advanced nanomaterials for fabrication of high-performance polymer composites. Recently, CNTs are used as fillers in SPEEK to overcome the DS dependent problems.

The major risk for using CNTs to modify PEMs in fuel cells is possible short-circuiting due to the excellent electrical conductivity of CNTs. Inspired by the electronic shied effect of silica and the excellent water retention, silica-coated CNTs ( $\left.\mathrm{SiO}_{2} @ \mathrm{CNTs}\right)$ were successfully prepared by a simple sol-gel process and then used as a new additive in the preparation of SPEEK-based composite membranes by Cui $\mathrm{Li}$ et al. [23]. The insulated and hydrophilic silica, coated on the surface of CNTs, not only eliminated the risk of short-circuiting, but also enhanced the interfacial interaction between CNTs and SPEEK, and hence promoted the homogeneous dispersion of CNTs in the SPEEK matrix. Moreover, compared to the pure SPEEK membrane $\left(3.42 \times 10^{-7} \mathrm{~cm}^{2} / \mathrm{s}\right)$, the methanol permeability of the $\mathrm{SPEEK} / \mathrm{SiO}_{2} @ \mathrm{CNT}$ composite membrane, with $\mathrm{SiO}_{2} @ \mathrm{CNT}$ loading of 5 wt.\%, exhibited almost one order of magnitude decrease of methanol crossover. While the proton conductivity still remained above $10^{-2} \mathrm{~S} \mathrm{~cm}^{-1}$ at room temperature. The obtained results display the possibility of $\mathrm{SPEEK} / \mathrm{SiO}_{2} @ \mathrm{CNT}$ membranes to be served as high-performance PEMs in direct methanol fuel cells.

Nanohybrid membranes of electrically aligned functionalized carbon nanotube (f CNT) with SPEEK have been successfully prepared by solution casting [43]. Functionalization of CNTs was achieved through a carboxylation and sulfonation route. A constant electric field $\left(500 \mathrm{~V} \mathrm{~cm}^{-2}\right)$ was applied to align the CNTs in the same direction during the drying process of the membranes. All the membranes were characterized chemically, thermally, and mechanically. The proton conductivity and methanol crossover resistance were evaluated to reveal their potential for direct methanol fuel cell application at temperature of $30{ }^{\circ} \mathrm{C}-90^{\circ} \mathrm{C}$.

The results showed that the incorporation of aligned CNT reasonably increases the ion-exchange capacity, water retention, and proton conductivity while it reduced the methanol permeability. The maximum proton conductivity $\left(4.31 \times 10^{-2} \mathrm{~S} \mathrm{~cm}^{-1}\right)$ was found in the SsCNT5 nanohybrid PEM with higher methanol crossover resistance. The prepared membranes can be used as electrode material in fuel cells and batteries.

The continuous carbon nanofibers (CCNFs) could be easily blended with SPEEK matrix and uniformly dispersed in an electrolyte polymer membrane. Youbo Di et al. incorporated CCNFs into SPEEK to prepare composite membrane for application in PEMs [38]. The characterization of the composite membranes revealed that, all dense composite membranes have excellent water swelling, high mechanical performance, good proton conductivity, and low methanol permeability. The composite membrane with $0.51 \mathrm{wt} \% \mathrm{CCNFs}$ displayed proton conductivity of $0.041 \mathrm{~S} \mathrm{~cm}^{-1}$ at room temperature and was fully hydrated. Moreover, the relative selectivity of the hybrid membrane with 2.52 wt.\% CCNFs was 1.5 times higher than that of pure SPEEK membrane. These results showed that the CCNF-supported SPEEK membranes are promising polyelectrolyte membranes for fuel cell applications.

From the above research on modification of SPEEK membranes with CNTs materials, we can find that, the $\mathrm{SPEEK} / \mathrm{SiO}_{2} @ \mathrm{CNT}$ composite membranes possess excellent thermal property and methanol barrier performance, as well as relatively high proton conductivity of the. The incorporation of electrically aligned functionalized CNT increases the ion-exchange capacity, water retention, and proton conductivity while it reduces the methanol permeability of the SPEEK composite membranes. Intermolecular interactions between the components in composite membranes were established. The higher proton conductivity and methanol crossover resistance reveal their potential for direct methanol fuel cell application at the temperature of $30^{\circ} \mathrm{C}-90^{\circ} \mathrm{C}$. With the assistance of continuous CCNFs, the obtained $\mathrm{CCNF} / \mathrm{SPEEK}$ membranes have condensed and uniform structures, as well as good mechanical, thermal, and dimensional stabilities. The water uptake and proton conductivity are improved. The composite membranes exhibit relatively low methanol permeability when the contents of CCNFs are controlled. These CCNF/SPEEK membranes are promising materials for PEMFC applications.

\subsection{Modification of SPEEK membranes with other inorganic materials}

A recent approach to enhance the proton conductivity is to prepare organic-inorganic composite membranes by incorporating SPEEK and fast proton conductors such as zirconium phosphate sulfophenylenphosphonate, heteropolyacids, and boron phosphate. The hydrophilic nature and excellent water absorption properties of aluminium phosphate $\left(\mathrm{AlPO}_{4}\right)$ make it an ideal candidate as molecular sieves for various applications.

Composite membranes of SPEEK with different weight ratios of $\mathrm{AlPO}_{4}$ synthesized by sol-gel were prepared by Vijay Shankar Rangasamy et al. [17]. The prepared $\mathrm{AlPO}_{4}$ was used as inorganic filler to enhance the thermal and mechanical stability and the water retention properties of SPEEK membranes. In that study, PEEK was non-homogeneously sulfonated using concentrated $\mathrm{H}_{2} \mathrm{SO}_{4}$ at different temperatures (room temperature, $60{ }^{\circ} \mathrm{C}$, and $80{ }^{\circ} \mathrm{C}$ ) and time durations (5, 7, 48, and $72 \mathrm{~h}$ ). Depending on the DS, the IEC of the membranes varied from 1.06 to $2.9 \mathrm{meq} \mathrm{g}^{-1}$. The water uptake of the membranes increased with DS. The composite membranes showed better thermal and mechanical stability and swelling behavior than the 
pure SPEEK membranes, however, the water uptake and proton conductivity of the composite membranes were lower than that of pure SPEEK membranes.

Phosphoric acid (PA) doped imidazolium ionic liquid polymer composite membranes were fabricated by immersing the membranes based on imidazolium ionic liquid and polymers of SPEEK or polyvinylidenefluoride (PVDF) into pure phosphoric acid at room temperature [44]. Imidazolium ionic liquids of 1-butyl-3methylimidazolium hexafluorophosphate $\left(\mathrm{BMIMPF}_{6}\right)$ or 1butyl-3-methylimidazolium dihydrogenphosphate $\left(\mathrm{BMIMH}_{2} \mathrm{PO}_{4}\right)$ link phosphoric acid molecules to polymer matrix. SPEEK is suitable to capture imidazolium ionic liquid owing to the strong interaction between imidazolium ionic liquid cations $\left(\mathrm{BMIM}^{+}\right)$and sulfonic acid group ($\mathrm{SO}_{3}{ }^{-}$). So the composite membranes based on SPEEK show prospects for high temperature PEMs.

Although all the components influenced the conductivity values of these composite membranes, phosphoric acid molecular chains played dominant role in the proton conduction. Proton conductivity of SPEEK/50\% $\mathrm{BMIMPF}_{6} / 4.6 \mathrm{PA}$ membrane at a level of $3.0 \times 10^{-2} \mathrm{~S} \mathrm{~cm}^{-1}$ was achieved at $160{ }^{\circ} \mathrm{C}$ under anhydrous conditions. Although the tensile stress at break decreased from $3.12 \mathrm{MPa}$ to $0.10 \mathrm{MPa}$ when the temperature increased from room temperature to $160{ }^{\circ} \mathrm{C}$, the SPEEK/50\% BMIMPF $_{6} / 4.6 \mathrm{PA}$ membrane still possessed stable conductivity of $2.0 \times 10^{-2} \mathrm{~S} \mathrm{~cm}^{-1}$ after remaining more than $600 \mathrm{~h}$ at $160{ }^{\circ} \mathrm{C}$.

Ren Suzhen et al. fabricated SPEEK/phosphotungstic acid-polyaniline (SPEEK/HPW-PANI) membranes by in situ polymerization of aniline for the purpose of decreasing the weight loss of HPW in the membranes [45]. They synthesized the SPEEK/HPW hybrid membrane and coated PANI on the membrane surface. The scanning electronic microscopy (SEM) images showed that HPW had good compatibility with SPEEK polymers, and energy dispersive X-ray spectroscopy revealed the successfully doping with HPW and polymerization of PANI. The surface of SPEEK/HPW-PANI became more compact than that of SPEEK/HPW and pure SPEEK, which would reduce the water uptake and swelling property. The proton conductivity of the SPEEK/HPW-PANI-5 composite membrane $\left(0.0915 \mathrm{~S} \mathrm{~cm}^{-1}\right.$ at $\left.80{ }^{\circ} \mathrm{C}\right)$ was higher than that of pure SPEEK membrane $\left(0.0687 \mathrm{~S} \mathrm{~cm}^{-1}\right.$ at $\left.80{ }^{\circ} \mathrm{C}\right)$. The thermal stability, for both SPEEK/HPW and SPEEK/HPW-PANI membranes, were higher than the pristine SPEEK membrane. The PANI is a good coating material for SPEEK/HPW hybrid membrane, which improves the hydrothermal stable properties. The SPEEK/HPW PANI shows promise performance for PEMs.

As a strong Bronsted acid, the phosphorus wolframic acid (PWA) has good conductivity. Composite membranes, prepared with PWA and SPEEK, can improve proton conductivity, and maintain methanol permeability simultaneously. Tong Juying et al. doped PWA and $\mathrm{Y}_{2} \mathrm{O}_{3}$ in SPEEK, with relatively high DS, to raise the methanol permeability of the membranes [21]. They gained $\mathrm{PWA} / \mathrm{Y}_{2} \mathrm{O}_{3} / \mathrm{SPEEK}$ membranes through reaction of SPEEK with concentrated $\mathrm{H}_{2} \mathrm{SO}_{4}$ at $60{ }^{\circ} \mathrm{C}$. The results show that the methanol permeation coefficient is as low as
$4.353 \times 10^{-7} \mathrm{~cm}^{2} / \mathrm{s}$. However, losing of PWA in water will influence the proton conductivity.

Functionalized titania was used as fillers to modify the SPEEK membrane to improve proton conductivity and methanol barrier property by Yin Yongheng et al. [46]. The functionalized titania sol containing proton conductive carboxylic acid groups or amino acid groups was derived from a facile chelation method using different functional additives. Then the novel SPEEK/carboxylic acidfunctionalized titania (SPEEK/TC) and SPEEK/amino acid-functionalized titania (SPEEK/TNC) hybrid membranes were fabricated via in situ sol gel method. The anti-swelling property and thermal stability of hybrid membranes were enhanced owing to the formation of electrostatic force between SPEEK and titania nanoparticles. The hybrid membranes exhibited higher proton conductivity than plain SPEEK membrane because more proton transfer sites were provided by the functionalized titania nanoparticles. Particularly, the proton conductivity of SPEEK/TNC membrane with $15 \%$ filler content reached up to $6.24 \times 10^{-2} \mathrm{~S} \mathrm{~cm}^{-1}$, which is 3.5 times higher than that of the pure SPEEK membrane. The SPEEK/TNC membranes possess the lowest methanol permeability because the acid-base interaction between sulfonic acid groups in SPEEK and amino groups in functionalized titania leads to a more compact membrane structure.

Recently, strong appear to develop PEM for fuel cell, that can work at high temperature under dry condition, makes the Ionic liquids (ILs) attractive due to their excellent chemical and thermal stability, wide electrochemical windows and temperature liquid range, and good ionic conductivity [47]. Singh Malik et al. prepared composite membranes based on SPEEK (DS $70 \%-72 \%$ )/ethylene glycol (EG)/IL by solution casting method, using water: ethanol (50:50) mixture as solvent, 1-butyl-3-methyl imidazolium trifluromethanesulfonate ([bmim][OTf]) as aprotic hydrophilic ionic liquid, and IL as ion charge carrier at high temperature $\left(30^{\circ} \mathrm{C}-140{ }^{\circ} \mathrm{C}\right)$. The EG was used as a cross-linker to reduce the leaching out of ionic liquid and enhance the mechanical strength of SPEEK membranes. Several membranes were prepared by keeping ratio of SPEEK:EG constant $(67: 33$ (wt.\%)) and varied the amount of ionic liquid (30, 40, 50, 60 and $70 \mathrm{wt} . \%)$. The effect of ionic liquid content on proton conductivity, structural, mechanical, thermal properties was evaluated. The cross-linking of SPEEK was carried out by thermal treatment for $2 \mathrm{~h}$ at $80^{\circ} \mathrm{C}, 100{ }^{\circ} \mathrm{C}, 120^{\circ} \mathrm{C}$, and $135^{\circ} \mathrm{C}$ for $16 \mathrm{~h}$ respectively. The results showed that the proton conductivity of all the membranes was in the range of $10^{-3} \mathrm{~S} \mathrm{~cm}^{-1}$, under $30^{\circ} \mathrm{C}-140{ }^{\circ} \mathrm{C}$ and anhydrous conditions, the proton conductivity increased when the temperature and amount of ionic liquid were raised. The good compatibility between IL and polymer matrix softed the composite membranes due to the plasticizing effect of IL. These membranes are promising materials for high temperature polymer electrolyte fuel cells.

Reviewing of the modification of SPEEK membranes with other inorganic materials, we know that, the $\mathrm{AlPO}_{4}$ prepared by sol-gel can enhance the thermal and mechanical stability and the water retention properties of 
SPEEK membranes. But the water uptake and proton conductivity of the composite membranes are lower than that of pure SPEEK membrane. The water uptake of the membranes depends on the DS. The proton conductivity of the $\mathrm{SPEEK} / 50 \% \mathrm{BMIMPF}_{6} / 4.6 \mathrm{PA}$ membrane remains stable during $600 \mathrm{~h}$ at $160^{\circ} \mathrm{C}$. The tensile stress decreases with the raise of temperature. The PANL layers reduce the weight loss ratio of HPW in the SPEEK/HPW hybrid membranes. The SPEEK/HPW-PANI membranes show higher conductivities, slightly increased thermal stability than the pure SPEEK membrane, and the water uptake and swelling ratio in volume of membranes decrease with increasing the PANL layers. The formation of electrostatic force between SPEEK and titania nanoparticles raises antiswelling property and thermal stability of hybrid membranes, SPEEK/TC and SPEEK/TNC. More proton transfer sites provided by the functionalized titania nanoparticles improve proton conductivity of the hybrid membranes. The proton conductivity of the composite membranes SPEEK/EG/IL are about $10^{-3} \mathrm{~S} \mathrm{~cm}^{-1}$ under $30{ }^{\circ} \mathrm{C}-140{ }^{\circ} \mathrm{C}$ at anhydrous conditions. The proton conductivity improves with the increase of temperature and amount of ionic liquid. The plasticizing effect of IL softens the composite membranes. The composite membranes have higher thermal stability and are promising for high temperature polymer electrolyte fuel cells.

\section{PROPOSALS FOR FUTURE WORKS}

The SPEEK membranes are the key components for the PEMs. The proton exchange capacity, water uptake, and conductivity of the SPEEK membranes are closely related to the structure, stability, mechanical and electrochemical property and methanol permeation of the PEMFC. As one new modern power, the SPEEK membranes, with good comprehensive properties, are highly competitive to replace Nafion membranes, and will be expected to be utilized in aviation, military and other industries. According to the above literatures, the advantages and disadvantages of membranes prepared by different methods are summarized in table1. And the following aspects need to be further investigated:

- break-through the difficulties of achieving PEM suitable for high temperature, humidity, and pressure environment;

- develop the fuel cell with stable properties, and enhance the oxidative and hydrolytic stability of system operation;

- analyze the content relationship of SPEEK and different polymers, so as to improve the main properties of the composite membranes;

- promote the interaction between SPEEK and other polymers to increase their compatibility and decrease phase separation;

- adjust the proper proportion of inorganic matter added in polymer to avoid brittleness and hardness of the membrane;

- raise the affinity of membrane with water, so as to increase the proton conductivity;

- improve the distribution of inorganic particles in the membrane in case they influence the conductivity, the tensile strength, and thermal stability of the composite membrane;
- increase the dimensional stability of the membrane under dry and wet conditions to prevent the internal stress accumulation and decline of performance and life expectancy.

- enhance the strength of the membrane to overcome the fragile, peel, and damage of composite membrane;

- develop thick and dense membrane to improve the methanol resistance;

- reduce the diameter of the inorganic particles to increase the specific surface area, and gain good conductivity;

- research the interface connection between the membrane and the electrode to maintain high proton exchange and low methanol permeability.

Table 1. Advantages and disadvantages of modified membranes

\begin{tabular}{|l|l|l|}
\hline Membranes & Advantages & Disadvantages \\
\hline $\begin{array}{l}\text { Blend } \\
\text { membranes }\end{array}$ & $\begin{array}{l}\text { Swelling and permeability reduced } \\
\text { effectively, good compatibility }\end{array}$ & $\begin{array}{l}\text { Proton conductivity } \\
\text { is content dependent, } \\
\text { phase separation }\end{array}$ \\
\hline $\begin{array}{l}\text { Cross-linked } \\
\text { membranes }\end{array}$ & $\begin{array}{l}\text { Significantly improved chemical, } \\
\text { thermal and dimensional stability, } \\
\text { sharply reduced methanol } \\
\text { permeability }\end{array}$ & $\begin{array}{l}\text { Proton conductivity } \\
\text { reduced and content } \\
\text { dependent }\end{array}$ \\
\hline $\begin{array}{l}\text { Membranes } \\
\text { modified with } \\
\text { other polymers }\end{array}$ & $\begin{array}{l}\text { Good thermal, dimensional and } \\
\text { oxidative stability, and mechanical } \\
\text { property, improved water uptake } \\
\text { and methanol permeability }\end{array}$ & $\begin{array}{l}\text { Proton conductivity } \\
\text { need to be raised }\end{array}$ \\
\hline $\begin{array}{l}\text { Membranes } \\
\text { modified with } \\
\text { SiOn materials }\end{array}$ & $\begin{array}{l}\text { Low methanol permeability, } \\
\text { increased thermal, dimensional } \\
\text { and mechanical stability, raised } \\
\text { swelling resistance }\end{array}$ & $\begin{array}{l}\text { Proton conductivity } \\
\text { need to be raised }\end{array}$ \\
\hline $\begin{array}{l}\text { Membranes } \\
\text { modified with } \\
\text { CNTs materials }\end{array}$ & $\begin{array}{l}\text { High proton conductivity and } \\
\text { methanol crossover resistance, } \\
\text { good thermal, dimensional and } \\
\text { mechanical stability, enhanced } \\
\text { intermolecular reaction }\end{array}$ & $\begin{array}{l}\text { Methanol } \\
\text { permeability and } \\
\text { proton conductivity } \\
\text { are content } \\
\text { dependent }\end{array}$ \\
\hline $\begin{array}{l}\text { Membranes } \\
\text { modified with } \\
\text { other inorganic } \\
\text { materials }\end{array}$ & $\begin{array}{l}\text { Good thermal, mechanical } \\
\text { stability, high and stable proton } \\
\text { conductivity }\end{array}$ & $\begin{array}{l}\text { Water uptake is DS } \\
\text { and content } \\
\text { dependent }\end{array}$ \\
\hline
\end{tabular}

\section{CONCLUSIONS}

In view of the pressing demand for renewable and clean energy in the world, the PEMFC was developed as a type of the modern power. In order to overcome the shortage of the traditional PEMs of PEMFC, SPEEK with high electric conductivity and low methanol permeability, as well as comprehensive property, was modified and expected to be used as PEMs.

The results of modification of SPEEK membranes with polymers show that, the methanol permeability of blend membranes SPEEK/PES-C are within the order of magnitude, $10^{-7} \mathrm{~cm}^{2} / \mathrm{s}$. The water uptake, swelling rate, and the proton conductivity of the SPPESK/SPEEK blend membrane are $101 \%, 34 \%$ and $0.212 \mathrm{~S} \mathrm{~cm}^{-1}$ at $80{ }^{\circ} \mathrm{C}$, respectively. The cross-linked SPEEK membranes have raised thermal and dimensional stability, yet reduced water uptake and methanol permeability than the pristine SPEEK membrane. The high loading of the cross-linker mixtures decrease the properties of the membranes. The non-solvent caused aggregation of the SPEEK ionomers, which then affected the structure and performance of the resultant membranes.

The results of modification of SPEEK membranes with inorganic materials show that, the SPEEK composite 
membranes, with $\mathrm{SiO}_{2}$ nanoparticles, indicate better thermal and mechanical stability, within a wider operational temperature range. The $\mathrm{SPEEK} / \mathrm{SiO}_{2}$ membranes exhibit conductivity of $0.187 \mathrm{~S} \mathrm{~cm}^{-1}$ and methanol coefficient of $9.72 \times 10^{-7} \mathrm{~cm}^{2} / \mathrm{s}$ at $80{ }^{\circ} \mathrm{C}$. The SPEEK/SSA composite membrane shows water uptake of $56.4 \%$, at $80{ }^{\circ} \mathrm{C}$. The composite membranes of SPEEK with POSS are thermally and mechanically stable up to $250{ }^{\circ} \mathrm{C}$, yet agglomeration appears. Incorporation of aligned CNT into SPEEK membranes increases the ionexchange capacity, water retention, and proton conductivity while it reduces the methanol permeability of the composite membranes. The SsCNT-5 composite membrane has the proton conductivity of $4.31 \times 10^{-2} \mathrm{~S} \mathrm{~cm}^{-1}$, as well as higher methanol crossover resistance. The proton conductivity of SPEEK/50\% $\mathrm{BMIMPF}_{6} / 4.6 \mathrm{PA}$ membrane maintains $2.0 \times 10^{-2} \mathrm{~S} \mathrm{~cm}^{-1}$ stably after remaining $600 \mathrm{~h}$ at $160^{\circ} \mathrm{C}$, whereas the tensile stress at break decreased. The PANI improves the hydrothermal stable properties. The methanol permeation coefficient of the composite membranes, prepared with PWA and SPEEK, is as low as $4.353 \times 10^{-7} \mathrm{~cm}^{2} / \mathrm{s}$. More proton transfer sites were provided by the functionalized titania nanoparticles which leads to more compact structure in the composite membranes.

From the above results we know that, the modification of SPEEK membranes displays good thermal stability, improved mechanical and proton conductive properties, and moderated water uptake and swelling compared to the original SPEEK membranes. The further investigation of SPEEK membranes is suggested to optimize the parameters and process of the preparation of SPEEK composite membranes to increase the electric conductivity, efficiency and performance of the fuel cell.

\section{REFERENCES}

1. Melinda, L.E., Yu, S.K., Marilyn, H., $\quad$ Lee, H.S., Mcgrath, J.E., et al. Toward Improved Conductivity of Solfinated Aromatic Proton Exchange Membranes at Low Relative Humidity Chemistry of Materials 20 2008: pp. 5636 - 5642.

2. Moonc, S.B., Kanga A.-S. Application of Polysulfone (PSf)-and Polyether Ether Ketone (PEEK)Tungstophosphoric Acid (TPA) Composite Membranes for Water Eelectrolysis Journal of Membrane Science 322 2008: pp. 154-161.

3. Ilaria, C., Maria, C., Marcello, R., Aldo, B.R. Application of a Neural Network Approach to the Electrophoretic Deposition of PEEK-alumina Composite Coatings. Materials Research Bulletin 44 2009: pp. 1494-1501.

4. Zhang, H.Q., Li, X.F., Zhao, C.J., Fu, T.Z., Shi, Y.H., Na, H. Composite Membranes Based on Highly Sulfonated PEEK and PBI: Morphology Characteristics and Performance Journal of Membrane Science 308 2008: pp. 66 - 74 .

5. Jaime, M., Marisol, M.G. The Use of PEEK Nanorod Arrays for the Fabrication of Nanoporous Surfaces under High Temperature :SiNx Example Nanoscal 4 2012: pp. 5608 - 5613 .

6. Xie, G.Y., Zhuang, G.S., Sui, G.X., Yang, R. Tribological Behaviour of PEEK/PTFE Composites Reinforced with Potassium Titanate Wwhiskers Wear 268 2010: pp.424- 430 .
7. Pan, G.L., Guo, Q., Zhang, W.D., Tian, A.G. Fretting Wear Behaviours of Nanometer $\mathrm{Al}_{2} \mathrm{O}_{3}$ and $\mathrm{SiO}_{2}$ Reinforced PEEK Composites Wear 266 2009: pp. 1208-1215.

8. Li, X.H. Application and Progress of New PEEK with High Temperature Resistance Transmission Technology of Fibre-Optical Cable 4 2010: pp. 44- 46.

9. Fu, H., Liao B., Qi, F.J., Sun, B.C., Liu, A.P., Ren, D.L. The Application of PEEK in Stainless Steel Fibre and Carbon Fibre Reinforced Composites Composites: Part B 39 2008: pp. 585-591.

10. Patrick, R.S., Bogna, S., Marco, W., Thomas, A., Christoph, H.F.H., Jens, F. Effect of Different Surface Pretreatments and Luting Materials on Shear Bond Strength to PEEK Dental Materials 26 2010: pp. 553-559.

11. Adolfo, L., Angelo, B. Sulfonated PEEK-based Polymers in PEMFC and DMFC Applications: A Review International Journal of Hydrogen Energy 37 2012: pp. 15241-15255.

12. Lin, P. Synthesis of SPEEK Cation Exchange Membrane and Its Application in Preparing Thioglyeolie Acid by Electroreduction. Master's Dissertation. Fujian Normal University. Tutor :Huang Xuehong. April, 2008.

13. Cansado, I.P.P., Gonçalves, F.A.M.M., Nabais, J.M.V., Ribeiro, C.M.M.L., Carrott, P.J.M. PEEK : An Excellent Precursor for Activated Carbon Production for High Temperature Application Fuel Processing Technology 90 2009: pp. $232-236$

14. Li, D., Guo, Q., Dong, Y.F., Tong, J.Y., Li, X., Li, M. A Study on Water Uptake and Swelling Property of High Sulfonation Degree SPEEK Based Composite Proton Exchange Membrane Symposium of the High Polymer Materials Science and Engineering. Nanchang, China, 2010.

15. Nisa, V.S., Rajesh, S., Murali, K.P., Priyadarsini, V., Potty, S.N., Ratheesh, R. Preparation, Characterization and Dielectric Properties of Temperature Stable $\mathrm{SrTiO}_{3} / \mathrm{PEEK}$ Composites for Microwave Substrate Applications Composites Science and Technology 68 2008: pp. $106-112$.

16. Lu, H., Jiang, C.P., Yang, X., Gu, J.L., Xu, C.C. Effect of Sulfonation Conditions on the Performance of SPEEK Membrane Chemical Research and Application 23 (6) 2011: pp. $690-693$.

17. Vijay, S.R., Savitha, T., Niels, D.G., Jin, W.S., Jean, P.L. Preparation and Characterization of Composite Membranes Based on Sulfonated PEEK and $\mathrm{AlPO}_{4}$ for PEMFCs Solid State Ionics 216 2012: pp. 83-89.

18. Hacer, D., Inan, T.Y., Murat, K., Metin, K. Organomontmorillonites and Sulfonated PEEK Nanocomposite Membranes for Fuel Cell Applications Applied Clay Science 52 2011: pp. 285-294.

19. Iulianelli, A., Clarizia, G., Gugliuzza, A., Ebrasu, D., Bevilacqua, A., Trotta, F., Basile, A. Sulfonation of PEEKWC Polymer via Chloro-sulfonic Acid for Potential PEM Fuel Cell Applications International Journal of Hydrogen Energy 35 2010: pp. 12688-12695.

20. Luo, H.Z., Guntars, V., Mkhulu, M. Cross-linked PEEKWC Proton Exchange Membrane for Fuel Cell International Journal of Hydrogen Energy 34 2009: pp. 8616-8621.

21. Tong, J.Y., Guo, Q., Li, D., et al. A Study on Methanol Permeation Resistance of PWA/ $\mathrm{Y}_{2} \mathrm{O}_{3} /$ SPEEK Composite Proton Exchange Membrane for Direct Methanol Fuel Cell Symposium of the Polymer Materials Science and Engineering 2010: pp. 262-263. 
22. Moonc, S.B., Kanga, A.S. Application of Polysulfone (PSf)-and Polyether Ether Ketone (PEEK)tungstophosphoric Acid (TPA) Composite Membranes for Water Electrolysis Journal of Membrane Science 322 2008: pp. $154-161$.

23. Cui, L., Geng, Q., Gong, C.L., Liu, H., Zheng, G.W., Wang, G.J., Liu, Q.M., Wen, S. Novel Sulfonated Poly (ether ether ketone)/Silica Coated Carbon Nanotubes Highperformance Composite Membranes for Direct Methanol Fuel Cell Polymer for Advanced Technologies 26 2015: pp. $457-464$.

24. Ma, J., Su, D.Y., Ni, H.J., Huang, M.Y., Wang, X.X. Performance of Sulfonated Polyether Ether Ketone Composite Membranes for Fuel Cell Applications International Journal of Nanoscience 14 (1) 2015: pp. 1460016-1-1460016-5.

25. Zhu, K., Lu, H., Chen, J.W., Gu, J.L., Xu, C.C., Lu, C., et al. Preparation of SPEEK/PES Blend Membranes for Vanadium Redox Flow Battery Guangzhou Chemical Industry 39 (11) 2011: pp. 38-40.

26. Gao, Q.J., Wang, Y.X., Xu, L., Wei, G.Q., Wang, Z.T. Studies on SPEEK/PES-C and SPEEK/SPES-C Blend Proton-exchange Membranes ACTA Polymerica Sinica 1 2009: pp. $45-47$.

27. Du, L.G., Wu, X.M., Yan, X.M., He, G.H. Preparation and Properties of Sulfonated Poly (phthalazinone ether sulfone ketone)/Sulfonated Poly (ether ether ketone) Blend Proton Exchange Membrane Polymer Materials Science and Engineering 28 (7) 2012: pp. 148-152.

28. Inan, T.Y., Hacer, D., Unveren, E.E., $\quad$ Ersoy, E. Sulfonated PEEK and Fluorinated Polymer Based Blends for Fuel Cell Applications: Investigation of the Effect of Type and Molecular Weight of the Fluorinated Polymers on the Membrane's Properties International Journal of Hydrogen Energy 35 2010: pp. 12038-12053.

29. Song, J.M., Shin, J., Sohn, J.Y., Young, C.N. Preparation and Characterization of SPEEK Membranes Cross-linked by Electron Beam Irradiation Macromolecular Research 19 (10) 2011: pp. 1082-1089.

30. Han, S.H., Zhang, M.S., Shin, J., Lee, Y.S. 1,6-Bis(4vinylphenyl)hexane as a Cross-linking Agent for the Preparation of Cross-linked Sulfonated Poly(ether ether ketone) Membranes by EB Irradiation Radiation Physics and Chemistry 97 2014: pp. 313-318.

31. Song, J.M., Lee, S.Y., Woo, H.S., Dong, S.W., Sohn, J.Y., Lee, Y.M., Shin, J. EB-cross-linked SPEEK Electrolyte Membrane with 1,4-Butanediol Divinylether/Triallyl Isocyanurate for Fuel Cell Application Journal of Membrane Science 469 2014: pp. 209-215.

32. Linda, C., Odile, F., Bruno, A., Regis, M., Serge, V., et al. Fluorohexane Network and Sulfonated PEEK Based SemiIPNs for Fuel Cell Membranes Journal of Membrane Science 389 2012: pp. 57-66.

33. Bi, C., Zhang, H.M., Zhang, Y., Xiao, S.H. Preparation and Application of Hydrophilic Treatment PTFE Reinforced SPPEK Composite Membrane for PEMFC Journal of South China Normal University (Natural Science Edition (Supplement) 2009: pp. 54-57.

34. Liu, D., Yates, M.Z. Tailoring the Structure of SPEEK/PDMS Proton Conductive Membranes through Applied Electric Fields Journal of Membrane Science 322 2008: pp. 256-264.
35. Li, H.T., Zhang, G., Ma, W.J., Zhao, C.J., Zhang, Y., et al. Composite Membranes Based on a Aovel Benzimidazole Grafted PEEK and SPEEK for Fuel Cells International Journal of Hydrogen Energy 35 2010: pp. 11172-11179.

36. Prasad, M., Smita, M., Sanjay, N.K. Polymer Electrolyte Membranes from Cloisite 30B-based Solid Proton Conductor and Sulfonated Polyether Ether Ketone/Polyvinylidene Fluoride-co-hexafluoro Propylene Blends for Direct Methanol Fuel Cells Royal Society of Chemistr Advances 4 2014: pp. 61178-61186.

37. Zhang, L.J., Zhao, S.X., Wang, Y.X. Effect of Nonsolvent on the Performance of Cast SPEEK Membranes Chemical Industry and Engineering 29 (6) 2012: pp. 26-30.

38. Di, Y.B., Yang, W.J., Li, X.J., Zhao, Z., Wang, M.R., Dai, J.M. Preparation and Characterization of Continuous Carbon Nanofibre-supported SPEEK Composite Membranes for Fuel Cell Application Royal Society of Chemistr Advances 4 2014: pp. 52001-52007.

39. Du, L. Preparation and Characterization of SPEEK Proton Exchange Membranes Doped with Acidified Inorganic Particles, Master's Dissertation. Dalian University of Technology. 2012.

40. Xu, D., Wang, Y., Zhang, Y., Zhang, G., Shao, K., Li, S.W., Na, H. Hybird Membrane with High Proton Conductivity and Selectivity Based on SPEEK for Direct Methanol Fuel Cells Chemical Research in Chinese Universities 26 (6) 2010: pp. 1031-1034.

41. Vijay, S.R., Savitha, T., Jean-Pierre, L. Sulfonated Poly(ether ether ketone)-functionalised Silica Composite Membranes for Applications in Proton Exchange Membrane Fuel Cells International Journal of Nanotechnology (9/10/11) 2014: pp. 971-974.

42. Deeksha, G., Veena, C. Non-fluorinated Hybrid Composite Membranes Based on Polyethylene Glycol Functionalized Polyhedral Oligomeric Silsesquioxane [PPOSS] and Sulfonated Poly(ether ether ketone) [SPEEK] for Fuel Cell Applications Reactive \& Functional Polymer 73 2013: pp. $1268-1273$.

43. Swati, G., Vaibhav, K. Dramatic Improvement in Water Retention and Proton Conductivity in Electrically Aligned Functionalized CNT/SPEEK Nanohybrid PEM American Chemical Society Applied Materials \& Interfaces 7 2015: pp. 264-272.

44. Che, Q.T., Zhou, L., Wang, J.L. Fabrication and Characterization of Phosphoric Acid Doped Imidazolium Ionic Liquid Polymer Composite Membranes Journal of Molecular Liquids 206 2015: pp. 10-14.

45. Ren, S.Z., Xu, M.L., Yang, Y., Ma, S.B., Hao, C. Effects of Microstructural Functional Polyaniline Layers on SPEEK/ HPW Proton Exchange Membranes Journal of Applied Polymer Science 131 2014: pp. 41033-41037.

46. Yin, Y.H., Xu, T., He, G.W., Jiang, Z.Y., Wu, H. Fabrication of Sulfonated Poly(ether ether ketone)-based Hybrid Proton-conducting Membranes Containing Carboxyl or Amino Acid-functionalized Titania by in Situ Sol-gel Process Journal of Power Source 276 2015: pp. $271-278$.

47. Rajender, S.M., Pawan, V., Veena, C. A Study of New Anhydrous, Conducting Membranes Based on Composites of Aprotic Ionic Liquid and Cross-linked SPEEK for Fuel Cell Application Electrochimica Acta 152 2015: pp. 352-359. 